\title{
Energy efficiency in universities: the need for guidance and a strategic approach
}

\author{
Sean Murray
}

Department of Civil \& Environmental Engineering, UCC.

\section{Efficiency's role in meeting targets}

The leaders of many countries are discussing ambitious targets for reducing emissions of greenhouse gases (GHGs) as a means of mitigating the worst impact of climate change on the environment and our economies. In 2007, EU leaders endorsed an integrated approach to climate change and energy policy. They committed Europe to transforming itself into a highly energy-efficient low carbon economy through their 20-20-20 targets, according to the European Commission, Climate Action. These targets are ambitious and consist of:

A reduction in EU greenhouse gas emissions of at least 20\% below 1990 levels

A commitment that $20 \%$ of EU energy consumption will come from renewable resources

A $20 \%$ reduction in primary energy use compared with projected levels, to be achieved by improving energy efficiency.

Figure 1, below, shows that the carbon dioxide equivalent of all greenhouse gases $\left(\mathrm{CO}_{2}\right.$ eq.) from the energy sector is the second greatest contributor of greenhouse gases. This fact creates an opportunity to explored ways to reduce the emissions from the energy sector. However, the methods need to be target the most significant culprits in a costeffective manner in order to the have maximum affect on the reduction of emissions from the energy sector.

(Source: EPA Environment in Focus website)

\section{Universities and the Energy Sector}

Universities and the energy sector would not be a marriage one would immediately think of but the connection between both will be enhanced by this research in the future. Universities worldwide are the source of education and the home to immeasurable amounts of research. The Carbon Neutral Buildings Project is one research project ongoing in University College Cork. The research is based on the retrofitting of existing building in the 


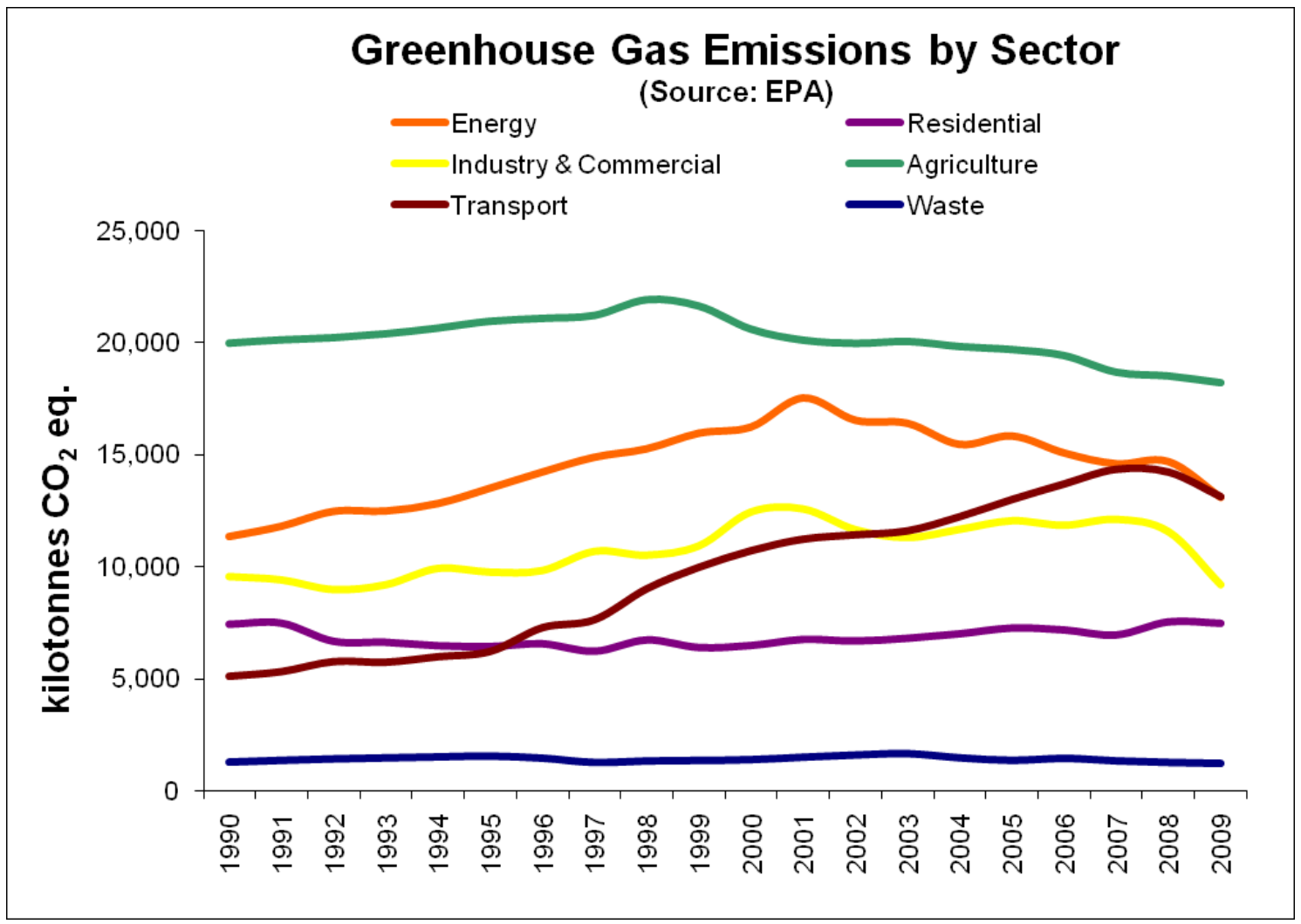

Figure 1: : Greenhouse Gas Emission fluctuation over time, by Sector

college campus and its aim is to remove barriers to the achievement of energy efficiency in existing buildings and, by association, to reduce carbon emissions.

In their make-up, universities have a vast amount of building stock at their disposal, buildings which range in age from tens to hundreds of years old and also greatly vary in size. A university's running costs is largely made up from its energy bill, as providing heating and lighting at the peak time energy-using time of the year, the winter, would be very expensive.

The afore-mentioned university buildings hold massive potential in the form of retrofit case-study buildings which would provide much needed data on retrofit performance, a lack of which exists according to the Rocky Mountain Institute, a leading United States research organisation. This university-created case-study data, coupled with the credibility associated with university research, holds great potential for universities to lead large strides in the energy sector.

\section{Focus of my research}

In general terms, retrofit means to modernise or expand using modified parts or equipment. In relation to current buildings, both domestic and non-domestic, retrofitting would 


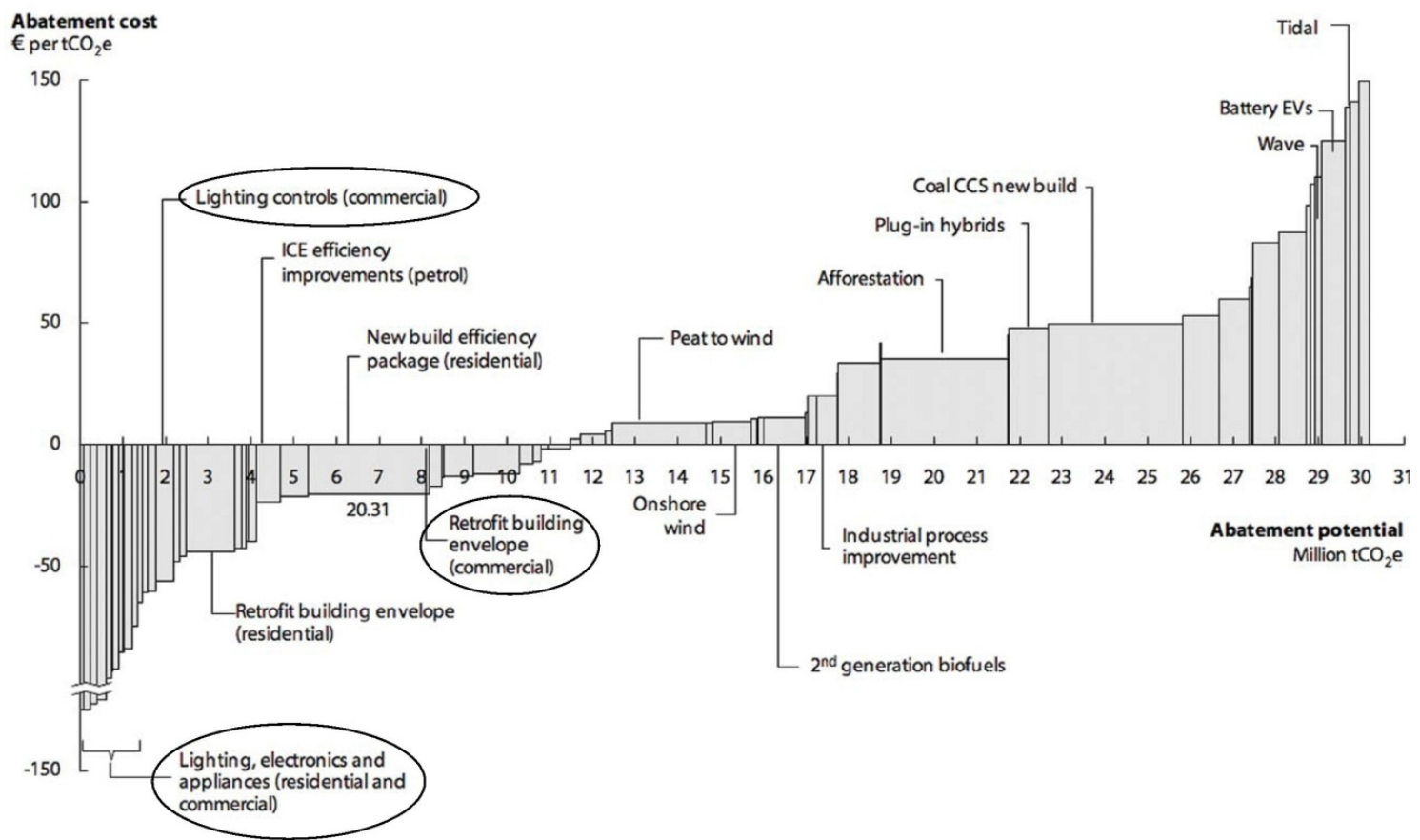

Figure 2: : Ireland's Greenhouse Gas reduction cost curve, illustrating that retrofitting commercial buildings has a negative net societal cost.

take the form, for example, of changing windows from single- or double-glazing to tripleglazing. Other examples would be such things as changing the lighting fittings or changing the heating system, or the heating system controls.

The achievement of energy efficiency in existing buildings can only be realistically achieved by retrofitting and therefore retrofitting is generally seen as an untapped resource. The benefits of retrofitting can be clearly seen in the Global GHG abatement cost curve, presented in Figure 2. The Greenhouse Gas Abatement Cost Curve, developed by McKinsey, estimates the prospective annual abatement/alleviation cost in euro's per ton of avoided emissions of greenhouse gases, as well as the abatement potential of these approaches in million tons of emissions.

The abatement cost is calculated as the annual additional operating cost less potential cost savings divided by the amount of emissions avoided. This formula implies that costs can be negative if the cost savings are considerable. From the Global GHG abatement cost curve, it can be seen that retrofitting has a negative cost associated with it, suggesting a savings potential.

(Source: SEAI's, Ireland's Low-Carbon Opportunity, An analysis of the costs and benefits of reducing greenhouse gas emissions, report.)The relationship between energy efficiency 
and society in general isn't overly strong but is slowly developing. The introduction of grants and incentives by the Irish Government, through the Sustainable Energy Authority of Ireland, such as the Better Energy Homes scheme on a domestic level or the Better Energy Workplaces on a non-domestic level has somewhat enhanced society's perception of energy efficiency. However, the lack of evaluation and subsequent data on the success of the schemes leaves a grey area in relation to energy savings achieved and also in relation to making a case for retrofitting in the future.

There are a number of methods to change this relationship between energy efficiency and society. One such method is the development of a decision-making software tool for retrofit analysis, which my research is focused on. This software too would allow building owners to realise the savings and incentives achievable by energy efficiency retrofits.

This retrofit tool will take in data about a building's geometry and physics, from which suggestions on retrofit measures could be made and the effectiveness of each measure could also be calculated. This allows building owners the use of a non-specialist software tool to calculate potential energy savings and carbon emissions and by association retrofit costs and payback periods. This tool would then provide society with case-studies and data to enhance the energy efficiency perception.

The development of this tool will be done through choosing a sufficient modelling technique to base the tool on, then developing a unique user interface for the software. The modelling technique chosen to be used will be based on the analysis of two case-study building on the campus of UCC.

\section{Case study buildings}

The Carbon Neutral Buildings Project, in co-operation with The Building and Estates Office of UCC, has instigated the retrofit of two buildings on campus, the Civil and Environmental Engineering Building and the Crossleigh building. The retrofit of the Civil \& Environmental Engineering Building took place during the summer of 2009 while the retrofit of the Crossleigh building took place a year later, during the summer of 2010. Both retrofit projects are outlined below.

\section{Civil \& Environmental Engineering Building — case study building no. 1}

The Civil \& Environmental Engineering building is located on the University's main campus and has been an integral part of the University since its early years. The building was designed by William Hill and constructed in 1910 and is now listed on the University's conservation plan. This status ensures that the external facade of the building is to remain 
intact and, to a certain point, has ensured that the majority of the building's original characteristics have also remained intact. The building, in its construction, consists of thick brick walls with an external plaster facade, single glazed windows and serious lack of lighting and heating control. This would be typical of many buildings of that era, not only across Universities in Ireland but also of other public sector and commercial buildings.

The pre-retrofitted building, in its multi-purpose state, sufficiently met the requirements of the academic staff and administrative staff as well as the requirements of the students. However, in terms of energy efficiency, thermal comfort and overall building performance, the building was sub-standard. With a heating system consisting of three single-pipe heating circuits running constantly for twelve hours per day for the entire heating season, lights that were on constantly from early morning to late at night without daylight harvesting or occupancy sensors fitted, and windows which had become gradually more leaky with every layer of paint added, there was major scope for improvement from an energy performance perspective.

The retrofit measures undertaken were:

Building Management System (BMS) installation, with integral weather compensation.

$\square$ Thermostatic Radiator Valves (TRV) installation.

Heat Meter installation.

Light fitting replacement along with Passive Infrared (PIR) sensors and Dimming Controls.

Insulation of the attic.

\section{Crossleigh Building - case study building no. 2}

The Crossleigh building, a former dwelling house, was acquired by the University in the 1940s, during a time when extra space was needed due to the University's expansion. Strategically located to the east of the original campus Quadrangle, it's first purpose was to provide a home for those who had been lodging in the East and West wings of the Quadrangle. The building is now the home of the Department of Applied Social Studies and has been so for the past number of decades.

There are many similarities between this building and the Civil \& Environmental Engineering building from a pre-retrofit point of view in that both buildings serve the needs of the occupants. However, given that the heating system consisted of electrical storage heaters, the oldest of which would have been up to 40 years old, control was possible but the energy performance of the system was poor. Also, the lighting fittings in place were the older, less efficient, T12 fittings without dimming controls and occupancy sensors. 
The retrofit measures undertaken in the Crossleigh building were:

Replacement of electrical storage heating system with a gas fuelled heating system.

Fitting of dry-lining insulation on all externally exposed walls.

Upgrading lighting fittings to high efficiency T8's to include occupancy and dimming controls.

Installation of heat meters to monitor heat usage in the building.

\section{Case study building analysis}

The analysis of the case study buildings will comprise of numerous tasks. These tasks, outlined below in Figure 3, will then form the basis for arguments for a certain modelling technique, which will be used to develop a decision-making software tool which in turn will be used to improve people's awareness of energy efficiency potential.

The tasks to be completed on both buildings will be pre-retrofit and post-retrofit monitoring and modelling. The monitoring will be in the form of monitoring actual energy usage in the buildings using meters installed as part of the retrofit project. The modelling takes the form of static simulation modelling and dynamic simulation modelling. The static simulation modelling is a simplified modelling technique, while the dynamic simulation modelling is a sophisticated technique requiring a lot more time and detail to complete.

The overall analysis of both retrofit projects will also provide a quantitative assessment of the achievement of the retrofits carried out.

\section{Improvements and future implications}

An energy assessment is a practical review and analysis of energy management and usage in a chosen target, like a building, with the objective of understanding the energy dynamics of the target under study. An energy assessment is typically carried out to ascertain methods by which energy usage can be reduced, without affecting the output/function. In terms of a building, the output/function would largely be the comfort levels of the occupants. An energy audit should first determine the significant energy users and then seek to prioritise the opportunities for energy savings, from the most to the least cost-effective.

Assessment of savings as a result of retrofit measures is not always as straight-forward as it might first appear. This is particularly true in the case of multiple retrofit measures taking place at the same time. For instance, upgrading a heating system to include weather compensation while also upgrading the lighting to lower energy consuming lights will mean that the full affect of the heating system upgrade will not be fully realised. This is due to the fact that the building will not have the same casual gains from the lights as 


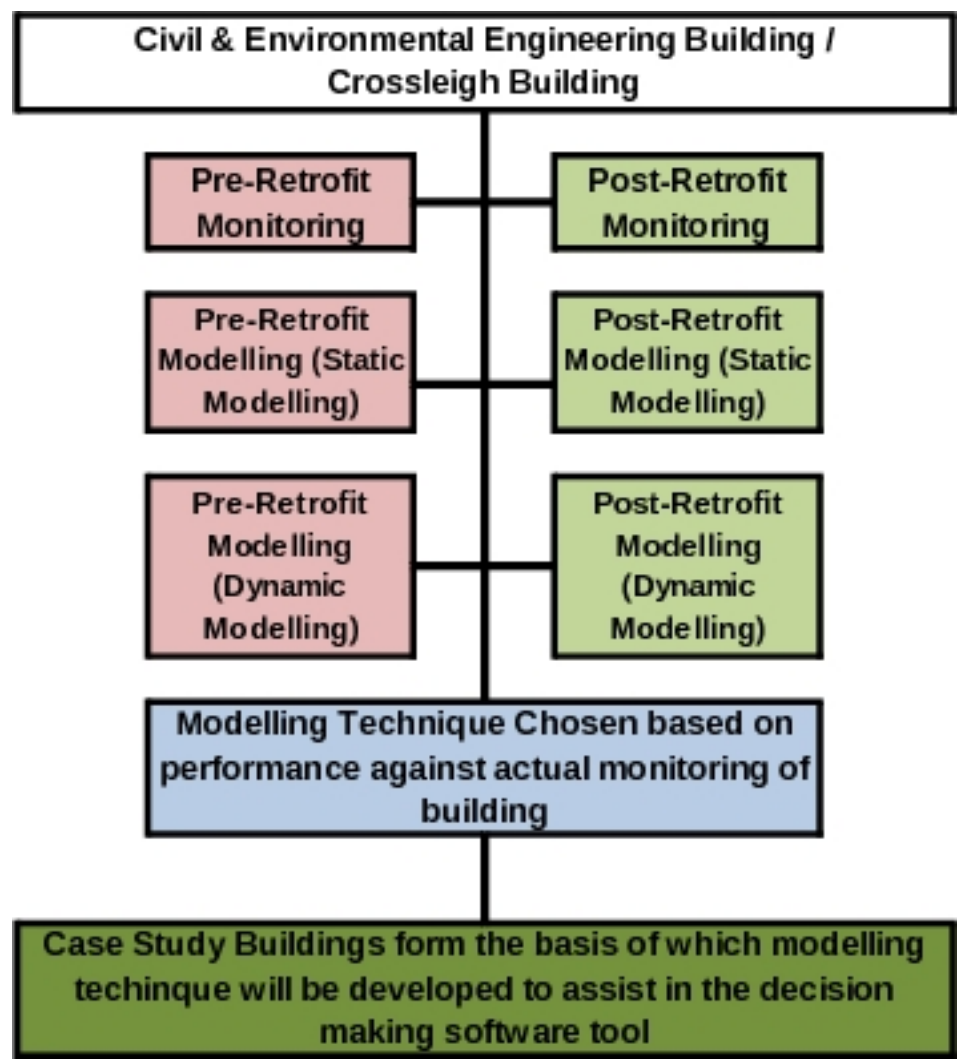

Figure 3: 3: Outline of procedure for Case Study Buildings Analysis

it had previously. Thus, the heating system will have to replace this heat gain lost in the lighting upgrade. It is our intention that the decision-making retrofit tool proposed in this research will consider such intricate interlinking of retrofit measures.

According to the World Coal Association, proven coal and gas reserves are equivalent to 46 and 63 years consumption at current production rates. From that perspective, "efficiency is better than fuel" and improving energy efficiency is being recognised by most incoming policy makers as the necessary first course of action in tackling the depleting fossil fuel supply.

The greatest barrier being cited in the prevention of widespread adoption of retrofits is the lack of data in retrofit performance in terms of energy savings and financial backing according to a Pike Research white paper in 2010. It is the aspiration of the Carbon Neutral Buildings Project to work on a solution to this finding, in the white paper, in the form of a user friendly, low cost, simplified modelling software tool which will assist building managers and practitioners alike in delivering greater energy efficiency and energy savings. It is envisaged that this tool will provide the data required on retrofit performance, whilst also reducing the high upfront costs of energy modelling. 


\section{Outlook for research}

Retrofitting is a method of achieving energy efficiency for buildings for the future. The initial capital cost investment, the associated payback and the scale of the retrofit all need to be considered when undertaking a retrofit project. These facts, coupled with the perceived barriers towards retrofits, highlight that there is a great need for guidance in this area. This need can also be seen to stem from the requirement to allow people to make a judgement on their own individual case, as each project's retrofit potential is different.

The form which the guidance should take could be one of many. Guidance documents could be seen to be the norm, being issued by the country's energy agency such as SEAI in the case of Ireland. However, documents can often be quite large, and can contain information which might be irrelevant to most people. This could then turn people off attempting to carry out retrofits. Furthermore, documents often tend to only deal with idealised situations, which try to capture as broad a range of buildings as possible. While this will help a certain proportion of users in some ways, it will inevitably lead to confusion, as every situation will be unique.

The Carbon Neutral Buildings Project sees the need for guidance as being the need for an alternative to a guidance document. It envisions an interactive application which is userfriendly, easily interpreted and basic in function. This would take the form of a software application with a straight-forward user interface. This software tool will have accurate output for a minimal input taking the form of basic building information.

This interactive application would assist energy managers or people who own or run non-domestic buildings and are looking at possible ways of cutting the running costs of the building. It will provide first hand evidence of the possible savings achievable from retrofits without the expense of complicated modelling or simulation. Payback periods for initial capital investment will also be included in the guidance tool to give a well rounded overall picture of the benefits to the proposed renovation which is being assessed.

Sean Murray is a student in the Department of Civil \& Environmental Engineering UCC, under the supervision of Dr. Dominic $O^{\prime}$ Sullivan and would like to thank Dominic for his contribution to this research. 